\title{
The Victim-Informed Prosecution Project: A Quasi-Experimental Test of a Collaborative Model for Cases of Intimate Partner Violence
}

\author{
Lauren Bennett Cattaneo \\ George Mason University \\ Lisa A. Goodman \\ Boston College \\ Deborah Epstein \\ Georgetown University Law Center, epstein@law.georgetown.edu \\ Laurie S. Kohn \\ Georgetown University Law Center, kohnls@law.georgetown.edu \\ Holly A. Zanville \\ George Mason University
}

This paper can be downloaded free of charge from:

https://scholarship.law.georgetown.edu/facpub/1361

http://ssrn.com/abstract=2182770

15 Violence Against Women 1227-1247 (2009)

This open-access article is brought to you by the Georgetown Law Library. Posted with permission of the author. Follow this and additional works at: https://scholarship.law.georgetown.edu/facpub

Part of the Criminal Law Commons, and the Law and Gender Commons 


\title{
The Victim-Informed \\ Prosecution Project: \\ A Quasi-Experimental Test \\ of a Collaborative Model for \\ Cases of Intimate Partner \\ Violence
}

\section{Lauren Bennett Cattaneo,' Lisa A. Goodman, ${ }^{2}$ Deborah Epstein, ${ }^{3}$ Laurie S. Kohn, ${ }^{3}$ and Holly A. Zanville'}

\begin{abstract}
The Victim-Informed Prosecution Project (VIP) was designed to amplify the voice of the victim in the prosecution of a battering current or ex-partner through collaboration between the prosecution and victim-centered agencies. This article describes the rationale for and design and implementation of VIP and then explores whether it increased perceived voice. While some VIP services (advocacy and civil protection order representation) were associated with increased perceived voice, the program as a whole was associated with it only in the context of greater contact with prosecutors, when cases were more likely to be felonies. We make specific recommendations for applying this model.
\end{abstract}

\section{Keywords}

advocacy, criminal justice system, intimate partner violence, program evaluation, service coordination, victim empowerment

The criminal justice system has long been at the heart of efforts to effectively intervene in cases of intimate partner violence (IPV; e.g., Fagan, 1996; Jordan, 2004). Over the past few decades, both law enforcement and prosecutorial responses to domestic violence have undergone substantial reform. Where in the past perpetrators were seldom arrested and even more rarely prosecuted, today the national trend is policy mandating arrest where

'George Mason University, Fairfax, VA

${ }^{2}$ Boston College, Chestnut Hill, MA

${ }^{3}$ Georgetown University Law Center,Washington, DC

Corresponding Author: Lauren Bennett Cattaneo, LCattane@gmu.edu. 
there is probable cause and prosecution where there is sufficient evidence. There is a striking and perhaps ironic parallel between past and current approaches, however. In the past, cases were generally not taken seriously, regardless of the victim's wishes. Today, the opposite is true; policy dictates that cases should be taken seriously, regardless of the victim's wishes. Despite the major progress that has been made, victims' voices do not play a large role in the criminal justice process.

There is evidence that IPV victims' lack of voice in the criminal process has a significant cost both for victim safety and well being and for the court's agenda (Bell, 2007; Epstein, Bell, \& Goodman, 2003; Zweig \& Burt, 2007), but the obstacles to addressing this issue are formidable. While both a prosecutor's office and a victim may hope to end the violence in the victim's life, the strategies they wish to employ to that end often conflict. Even when such conflicts do not exist, prosecutors' offices are notoriously overburdened, and attorneys lack the time or resources to sufficiently address concerns outside their main agenda: ensuring the accountability of the offender.

This article describes the Victim-Informed Prosecution Project (VIP), a program that, over its 6-year tenure, aimed to amplify the voice of the victim in the prosecution of IPV cases in Washington, D.C. Through collaboration between prosecutors and victimcentered agencies, it was hoped that the victim's perspective would be voiced by providers who had established a relationship with her and that the prosecution of the case would be carried out more in accordance with victim goals and concerns than in the normal course. As a result, we hope that the twin goals of victim safety and offender accountability would be given equal weight and that victims would feel heard in the court process. This represents a novel approach to coordination, the current priority in IPV services, because it takes place throughout the life of the case rather than just at intake or through referral systems and includes the exchange of case-specific information. Communication among groups connected to a particular case has been identified as a significant challenge even in jurisdictions that have created specialized approaches to domestic violence cases (see Gavin \& Puffett, 2005); VIP represented a groundbreaking effort to create a model for such communication.

Future articles will explore the effectiveness of VIP for a variety of distal outcomes related to the case and the victim's well being. Here, we focus on the degree to which we were able to implement the program and affect change in our most proximal outcomevictim voice - defined as the extent to which victims felt they had been able to express their opinions and that those opinions had been valued and heard during the court process. Essentially, we ask whether in the best of circumstances, beginning with a funded program and enthusiastic partners, the significant obstacles referred to above can be overcome. In the sections that follow, we first overview the research and policy context that shaped the design of VIP, and next, we describe the program. We then describe data indicating the degree of implementation and the extent to which victims felt heard and understood. Finally, drawing on our experience, we identify future directions for program developers and policy makers interested in innovation to ameliorate the criminal justice system's response to IPV. 


\section{Victim Informed Prosecution}

\section{Context:The Criminal Justice System's Response to IPV}

The most recent wave of IPV advocacy in the criminal justice arena has focused on mandatory intervention policies. For prosecutors' offices across the country, including Washington, D.C., this has taken the form of "no-drop" policies that dictate that once a domestic violence case has been charged, the prosecutor should pursue that case regardless of the victim's preferences or willingness to provide testimony. Under such a policy, prosecutors encourage victims to participate in the prosecution but clearly communicate that decisions about the viability, scope, and nature of the case will remain solely with the prosecutor's office. These policies have dramatically increased both the number of domestic violence cases being pursued within the criminal justice system and the conviction rates in those cases.

While these changes have been strenuously promoted by many battered women's advocates, there are significant problems with the current landscape (e.g., Erez \& Belknap, 1998; Gillis et al., 2006). The prosecution's focus on punishing an offender for the most recent instance of abuse may or may not meet the needs of any particular victim, and may or may not be the most effective way to prevent future violence in any particular case (Epstein et al., 2003). In many cases, the relationship between the perpetrator and the victim that preceded court involvement will continue to some degree, especially when there are children in common (Bennett, Goodman, \& Dutton, 1999). Taking the myriad complexities of this context into account, and receiving little if any information about the ongoing criminal case, many victims request that charges be dropped. Research indicates that $50 \%$ to $80 \%$ of domestic violence victims will seek to drop criminal charges either by requesting a dismissal or by failing to appear for criminal trials (Ford \& Regoli, 1993).

A study conducted in the late 1990s illustrated that when victims fail to cooperate with the prosecution, $64 \%$ of prosecutors' offices use out-of-court victim statements to witnesses, police officers, and 911 operators (Rebovich, 1996). However, in the past few years, the U.S. Supreme Court has substantially limited prosecutors' ability to use such statements in lieu of victim testimony (e.g., Crawford v. Washington, 2004; Davis and Hammon v. Washington, 2006). Now, for such statements to be admissible, prosecutors must prove that they were made when there was an ongoing emergency and not with the intention to support later criminal prosecution. Even before these Supreme Court cases, prosecutors in a no-drop jurisdiction frequently refused to grant a victim's request to refrain from testifying. Instead, victims were often subpoenaed and forced to testify (Hanna, 1996). Prosecutors operating in no-drop jurisdictions such as the District of Columbia are even more likely to force victims to testify against their wishes in the wake of these court decisions (Kohn, in press).

While there are certainly cases in which this mandatory approach ends up being effective - the victim may explain to her abusive partner that she had no choice about the prosecution, and the batterer may be deterred from future violence - in many cases, significant harm is done (Gillis et al., 2006; Landau, 2000). This harm may take two basic forms. First, the system may inadvertently increase the risk to the victim while she is 
involved in the court without taking steps to protect her (e.g., providing safe housing or holding the batterer) during this time. Second, if the victim experiences the justice system as coercive and unresponsive, she might well be alienated from using it as a resource in the future (Epstein, 2002; Fleury-Steiner, Bybee, Sullivan, Belknap, \& Melton, 2006; Hotaling \& Buzawa, 2003).

One alternative possibility - that prosecutors act in accordance with victims' wishes, whatever they may be - is enormously problematic as well, not least because of the power it cedes to the batterer, who may have considerable ability to coerce the victim into requesting that charges be dropped (Epstein et al., 2003). Instead, we and others argue that there is potential for aggressive prosecution to benefit the victim, if it is tailored to address her particular situation (Bell, 2007; Epstein et al., 2003; Fleury-Steiner et al., 2006; Lewis, 2004). The VIP program, which ran from 2001 to 2007 at the District of Columbia U.S. Attorney's Office, was an effort to do just that. By design, the services received in the VIP program differed from services-as-usual in two ways. First, victims received intensive services from civil lawyers and advocates throughout their involvement in the system. Second, because of the coordination among civil lawyers, advocates, and the prosecutor's office, the criminal and civil cases in which the victim was involved were strengthened, and her voice in the criminal prosecution was amplified. Next, we describe these elements of the program in greater detail.

\section{Services Provided to VIP Participants Versus Services-As-Usual}

Advocacy. Advocates from the District of Columbia Coalition Against Domestic Violence provided VIP clients with crisis intervention and supportive counseling services and referred them to necessary social, financial, housing, employment, and psychological services. While all victims have access to these advocates on the day they initiate their cases at the court, follow-up usually is sporadic because of the volume of cases. In the normal course, an advocate sees between 30 and 50 new cases each week and can only follow up with a subset (E. Olds, personal communication, October 1, 2007). In contrast, the VIP advocate was responsible only for VIP clients (a total of 42 cases by the end of the project, with approximately four active cases at a time) and made frequent contact both on the phone and in person during court hearings. The advocate also maintained extensive contact when the participant was receptive throughout the pendency of the criminal case.

Such services are likely available from advocates in many jurisdictions, in varying levels of intensity depending on caseload. There are two important differences in the services provided to VIP participants. First, advocates were from a community-based organization rather than being employed by the court. While court-based advocates can do vital work, there are constraints and pressures associated with their institutional affiliation. Community-based advocates are not affected by the agenda of the prosecutor's office and are thus unconstrained in their ability to focus on the victim's agenda (Epstein et al., 2003). Second, these community-based advocates had access to the VIP prosecutors; this coordination profoundly affected their work with victims, as described later. 
Legal representation. As with any civil case (as opposed to criminal) in any jurisdiction, petitioners for a civil protection order (CPO) do not have to be represented by attorneys, and in the vast majority of cases they are not. In the VIP program, however, legal representation in the $\mathrm{CPO}$ case was provided to all participants by supervising attorneys and law students at Georgetown University Law Center's Domestic Violence Clinic, who supplied informal advocacy, legal representation in court, and coordination of services and information between each VIP team member. These student-lawyers work on one case at a time and therefore generally are able to devote a large number of hours to each client as they prepare for their CPO hearings 2 to 4 weeks from the initial intake. Supervisors from the Clinic carried independent caseloads unassociated with the program and then oversaw one to two VIP cases at a time.

Prosecution. The United States Attorney's Office (USAO) provided the team with prosecutors $^{1}$ from the Domestic Violence Unit who, as with services-as-usual, charge and litigate all domestic violence cases. Misdemeanor attorneys in this unit carry a caseload of 150 to 200 cases at a time, and felony attorneys carry 20 to 30 cases. The difference between the prosecution of services-as-usual and VIP cases was the fact that the prosecutor in charge of the VIP program at the USAO attended VIP meetings and oversaw VIP cases within the USAO, acting as a liaison between VIP partners and with the prosecutors handling the cases.

\section{Coordination Among VIP Partners Versus Services-As-Usual}

Whereas services similar to those described above might exist in various forms in other jurisdictions, the heart of VIP was the coordination among its partners. As detailed later, we encountered some obstacles to sustaining the coordination we envisioned at the start of the program. Here we describe the model as it was designed. Normally, the USAO would have little to no communication with advocates or civil lawyers concerning a victim in a domestic violence case. Neither the time nor the vehicle exists, and there is no tradition of collaboration across the civil and criminal justice systems. VIP was designed so that team members would meet twice a month to discuss case progress and victim needs and desires and would communicate between meetings when the need arose. Meetings would primarily consist of information sharing. Within the confines of confidentiality and victim consent, VIP partners would share information on the progress of the criminal and civil cases, exhibits for trial, and witness identities; would collaborate on testimony; and would discuss the victim's concerns and circumstances. Team members would also meet collectively with victims in an attempt to minimize the need to repeat often painful personal information about the abuse.

In the VIP model, civil lawyers and advocates were to act as intermediaries between victims and prosecutors in both directions. By communicating the perspective of victims to USAO prosecutors, they would work to ensure that all prosecutions were pursued in a manner maximally consistent with victim priorities and safety concerns. For example, an advocate or civil attorney might convince a prosecutor to include or decline to include 
certain charges, depending on the victim's relative comfort with testifying about a particular incident; they might influence the content of a plea offer (for example, when a victim felt strongly about the abuser admitting to an assault rather than merely to property damage). In addition, civil attorneys and advocates are likely to learn of a long history of violence the victim has suffered of which the prosecution typically is unaware. By sharing this information, they might convince the government to add charges that otherwise never would have been brought, including upgrading the case to a felony. In the normal course, a victim has no opportunity to influence the charges brought or the content of a plea offer. These decisions traditionally "belong" to the government and are made based on factors such as the nature and strength of the available evidence.

The additional information that civil attorneys and victim advocates could provide through VIP was also meant to facilitate the government's trust in the victim's story. Often, prosecutors who are insufficiently trained in the dynamics of domestic violence read inconsistencies in a victim's story or a seeming lack of emotion as certain evidence of untrustworthiness, and may make important case decisions based on these misconceptions (Epstein, 1999). A victim advocate or civil attorney would be able to help clarify the situation, either by providing a more in-depth factual background to explain an apparent inconsistency or by explaining the potential impact of depression or posttraumatic stress disorder on a victim's presentation. Again, because of the typical lack of coordination and information sharing between the government and civil attorneys or advocates, opportunities for such discussions are normally rare.

Informed by their coordination with VIP prosecutors, civil attorneys and advocates were also meant to promote greater trust in and understanding of the USAO by the victim. In general, they would seek to demystify the criminal process and explain the differences between the civil and criminal cases and the interests of the lawyers working on both cases. Although in services-as-usual advocates and others can explain the prosecutorial process to victims, such discussions are greatly facilitated by information sharing with the government. For example, a VIP victim could learn specifics about the probable timeframe for the prosecution's and the government's assessment of the likelihood of conviction after a contested trial. Further facilitating the victim's sense of trust in the system, information sharing was aimed to enable prosecutors to approach victims in a way that was maximally designed to address their concerns. With the advance knowledge of the victim's reservations regarding prosecution provided by civil advocates or attorneys, the government could address these concerns up front and avoid alienating her.

A final advantage to the coordination in VIP as it was designed was the facilitation of personal relationships among prosecutors, civil attorneys, and victim advocates. Such relationships could have an intangible but real effect on case management. Increasing levels of trust among members of the group would make it more likely that prosecutors would listen to and act on arguments presented by civil advocates regarding the severity of the case or the victim's safety concerns. In turn, this would help the victim feel more supported and safe. 


\section{Research Questions}

We now turn to the question of the extent to which VIP was implemented as it was designed, and whether it affected victim voice. In considering the timeframe for our questions, we noted that most victims' cases in the criminal system ended within 6 months, with the first 3 months being the most intensely active. Therefore, we were interested in the degree to which the program was implemented across two follow-up periods - 3 and 6 months. However, in asking about victim perceptions of their experience in court, we focused on the 6-month follow-up when they could look back over their experience as a whole. Specifically, we asked,

1. Was VIP implemented?

1a. At 3 and 6 months, did VIP participants report receiving more advocacy than services-as-usual?

1b. At 3 and 6 months, did VIP participants report receiving more legal advocacy in their CPO cases than services-as-usual?

1c. At 3 and 6 months, did VIP participants report more contact with prosecutors than services-as-usual?

1d. To what extent did the VIP partner agencies coordinate their services to VIP participants?

2. Looking back at their involvement with the court at 6 months, was VIP and each of its components associated with greater perceived voice for victims?

2a. Was participation in VIP associated with greater perceived voice?

$2 \mathrm{~b}$. Was more advocacy associated with greater perceived voice?

2c. Was more legal advocacy in the CPO case associated with greater perceived voice?

2d. Was more contact with the prosecution associated with greater perceived voice?

\section{Method}

\section{Participants}

We report here on the first 6 months of data collected in a 12-month evaluation of the VIP program, described further in forthcoming articles. Participants were 142 women recruited from the Domestic Violence Intake Center (DVIC) at the District of Columbia's Superior Court, where domestic violence criminal cases in Washington, D.C. are initiated. Eligibility criteria were developed by the VIP team and were designed to achieve consistency for the sake of the evaluation and to ensure that services by all of the team members were applicable. To this end, eligible women had come to the DVIC following the arrest of a male current or former intimate partner, wished to obtain a CPO, and their case had "prosecutorial merit" (defined as sufficient evidence to prove beyond a reasonable doubt that the 
accused committed the crime). Cases also had to meet a severity threshold: there was a history of physical abuse, threats to harm or stalking in the relationship, and either in the current incident or in the past, there had been a physical injury.

\section{Procedures}

A screening sheet, developed to identify cases that might meet eligibility criteria for VIP, was included in the packet of forms completed by every person entering the DVIC. A research assistant regularly collected these screens and approached eligible women in the waiting room to ask them if they would be interested in participating. This process was the same, regardless of whether the case ended up being a VIP or services-as-usual case. Research assistants explained that the project was part of an effort to improve services at the court and that participants would fill out a questionnaire that day and then be contacted by phone several times over the next 12 months. After reading the informed consent, if women agreed to participate, they were paid $\$ 10$ for filling out the initial questionnaire, which they generally had ample time to fill out during waiting periods during the court intake process, and research assistants were on site to answer questions and collect questionnaires. Approximately $20 \%$ of those who were approached refused to participate. Most common reasons for refusal were the need to attend to children, feeling too upset or distracted, or not having enough time.

The assignment of cases to VIP or the services-as-usual group also took place during the intake process at the DVIC and was based solely on the capacity of the VIP team. When VIP partners had the capacity to accept new cases, staff were on-hand in the DVIC to meet with victims and alert other members of the team that a new case had been identified. When any member of the team was at capacity, then VIP was considered unable to accept new cases. At these times, eligible cases were assigned to the services-as-usual group, and regular court staff met with victims in the DVIC as in the normal course.

At recruitment, participants also filled out a form giving detailed information about the best ways to get in touch with them over the next year, and other contacts research assistants might use to find them if they moved. Follow-up calls were conducted by trained, female graduate students in law or clinical psychology. Payments were $\$ 30$ for the 30-minute follow-up interviews at 3 and 6 months.

\section{Measures}

Demographics. For descriptive purposes, we gathered information on the victim's age, ethnicity, socioeconomic status (level of public assistance, employment, and education), and number of children.

Relationship with batterer and abuse severity. For the evaluation of VIP, we collected detailed information about the nature of the relationship between the victim and batterer at recruitment including its length and status and the level of physical and psychological abuse during the past year. We also tracked whether cases were designated misdemeanor or felony. We report these data here for descriptive purposes. We measured the level of 
physical abuse using a yes/no version of the Revised Conflict Tactics Scales (CTS; Straus, Hamby, Boney-McCoy, \& Sugarman, 1996). The items in each of three subscales ask if, in the past year, the respondent has experienced specific kinds of physical abuse, sexual coercion, or injury. We modified the sexual abuse subscale by removing items referring to the perpetrator "insisting" on sex without the use of force or threats and by adding, "I had sex with him because I was afraid of what he would do if I didn't." These modifications changed this subscale from seven to four items. This study used the total scale score, for which the Cronbach's alpha was .84.

We measured psychological abuse in the relationship with the Psychological Maltreatment of Women Inventory (PMWI)-Short Form (Tolman, 1999). Items ask about specific behaviors such as yelling and screaming, or watching over her activities at all times, and participants respond with a frequency rating $(0-5)$ which is then summed. This study used the total scale score, combining the Emotional-Verbal Abuse and Dominance-Isolation Subscales, for which the Cronbach's alpha was .89.

Degree of contact with the system. At each follow-up period, we asked all participants to report the number of contacts they had with system actors, including advocates, CPO lawyers, and prosecutors.

Nature of coordination. In collaboration with the VIP partner agencies, we developed items describing coordination among them. First, staff at Georgetown Law completed eight items detailing their relationship with the USAO in a particular case (e.g., "had a telephone relationship [with the USAO] as evidenced by repeated phone conversations and little problem with repeated failure to return calls;" "had meaningful discussions (i.e., both Georgetown and the USAO were receptive to the other's point of view) about charges, issuance of a warrant ... or other major decisions related to the criminal case-before these things happened"). Second, advocates completed a single item regarding their interaction with USAO: "Stayed with client through meeting with USAO." Finally, we developed a single item for whether representatives from the USAO, DCCADV, and Georgetown met as a group during the life of the case. A total of 10 individual yes/no items (see Table 3) were thus available to describe coordination in a particular case.

Victim voice. We measured the degree to which victims perceived they had voice in the court process with three items, each using a 4-point Likert-type scale $(1=$ strongly disagree, 4 = strongly agree). First, we adapted a three-item scale from Newmark, Harrell, and Salem's (1995) measure of court-related "empowerment" in custody cases. Removing an item specific to custody, we used the remaining two items: "I think the court considers my rights and wishes just as important as his rights and wishes," and "I feel the court treats me fairly and listens to my side of the story." We use "court" in the most general sense here, hoping to capture the entirety of the victim's contact with the system. The third item was developed for this study: "I got what I hoped for from pursuing a criminal case." Responses to items were summed, yielding a total score ranging from 4 to 12 . In these analyses, we were interested in victims' perspective on their level of voice at 6 months, looking back on their experience with the court. Cronbach's alpha at this time point was .74 . 


\section{Analysis Plan}

Missing data. There was a significant amount of attrition at each of our follow-up periods. Of our 142 participants, we reached $92(64.8 \%)$ at 3 months and 87 participants $(61.3 \%)$ at 6 months, with significantly better follow-up rates for VIP participants (see below). When we did not reach a participant at one follow-up but did reach her at the next, we filled in missing data when possible. For example, if a participant was not reached at 3 months, at the 6-month follow-up, we asked about contact with the advocate since the time of recruitment. As a result, there are data for 117 (82.4\%) participants at 3 months and 95 $(66.9 \%)$ at 6 months. Finally, because data were collected for the coordination items retrospectively, there were some cases for which items were missing; staff did not have access to sufficient information in the files to answer them.

Analyses. After evaluating the data for normality and outliers, we found that our outcome variable, perceived victim voice, was significantly skewed. We transformed it by taking its square root (Tabachnick \& Fidell, 2007). We then pursued two sets of analyses to address the research questions here. First, we tested for group differences (VIP vs. servicesas-usual) for each of the system contact variables at both 3 and 6 months, using $t$ tests for continuous variables and chi-square tests for dichotomous. Second, we investigated the relationship between the program elements and victim voice with a series of correlations (using Spearman's rho to account for extreme scores and ordinal scales), and $t$ tests.

\section{Results}

\section{Sample Description}

Table 1 gives descriptive statistics for demographic and abuse and case-related variables for both VIP and services-as-usual participants. The sample was primarily African American and low income, with about half of the participants unemployed, and a substantial minority receiving Temporary Assistance for Needy Families (TANF). The majority of the sample had a high school diploma or less at the time of recruitment. Almost three quarters of participants reported that they had an ongoing relationship with the perpetrator at the time of the abusive incident that brought them to court. Relationships averaged about 5 years in length but ranged from 1 month to 30 years. As is typical with a sample seeking help from the court (e.g., Bennett Cattaneo, Bell, Goodman, \& Dutton, 2007), levels of physical violence were high, with all but 4 participants experiencing at least one act of severe violence (e.g., he kicked her, burned her, used a knife or gun to assault her, or used threats or force to coerce her into sex) in the past year. Levels of psychological abuse were similarly high.

With respect to all of these variables but one, the VIP and services-as-usual groups were roughly equivalent, with no statistically significant differences. We found that VIP cases were more likely to be designated felonies than were services-as-usual cases, $\chi^{2}(1, N=$ 136) $=7.55, p=.01$. We did not find statistically significant differences between those we did and did not reach for follow-up in terms of level of violence, though we did have 
Table I. Descriptive Variables for VIP and Services as Usual Groups

\begin{tabular}{lcc}
\hline & VIP $(n=43)$ & Services-as-usual $(n=99)$ \\
\hline Age & $31.05(8.8 I)$ & $32.03(9.64)$ \\
Ethnicity is African American & $86.0 \%$ & $89.9 \%$ \\
Receiving TANF & $34.9 \%$ & $22.2 \%$ \\
Employed at least part-time & $41.9 \%$ & $55.1 \%$ \\
Highest level of education attained & & \\
$\quad$ Less than high school & $25.6 \%$ & $19.2 \%$ \\
High school & 58.1 & 65.7 \\
College/trade school & 16.3 & 11.2 \\
Post-college & 0 & 4.0 \\
Number of children she takes care of & $1.73(1.82)$ & $1.71(1.94)$ \\
Relationship length in months & $62.52(55.53)$ & $65.06(64.33)$ \\
Relationship intact & $72.1 \%$ & $71.0 \%$ \\
Physical abuse & $10.66(4.64)$ & $9.86(4.68)$ \\
Psychological abuse & $51.37(12.20)$ & $50.77(13.19)$ \\
Case designated misdemeanor & $73.8 \%$ & $91.5 \%$ \\
\hline
\end{tabular}

Note: For continuous variables, cell values = mean (standard deviation); VIP = Victim-Informed Prosecution Project; TANF = Temporary Assistance to Needy Families.

a. Relationship intact at time of incident leading to court involvement.

greater success in following up with our VIP group than with the services-as-usual group at 3 months $(95 \%$ vs. $77 \%), \chi^{2}(1, N=142)=7.14, p=.01$, and at 6 months $(79 \%$ vs. $61 \%)$, $\chi^{2}(1, N=142)=4.12, p=.04$.

\section{Degree of Contact With Staff}

Table 2 details the amount of contact participants reported they had with each of the VIP partners 3 and then 6 months after the beginning of their involvement with the system and highlights significant differences between the VIP and services-as-usual groups. Because of extreme scores, all of these variables were significantly skewed and were transformed prior to testing for group differences. Because of the large number of zeros at the 6-month follow-up, the level of contact for those variables was dichotomized as yes/no.

Advocates. The VIP group reported significantly more contact with advocates at both the 3- and 6-month follow-ups, $t(111)=-3.59, p<.01 ; \chi^{2}(1, N=90)=7.82$, $p<.01$. This difference was quite large in practical terms as well. At 3 months, half of the services-as-usual group had no contact with an advocate, and only $20.5 \%$ had more than two contacts. In the VIP group, less than a quarter had no contacts with an advocate, and almost $60 \%$ had more than two contacts. At 6 months, only $19 \%$ of services-as-usual participants reported some contact with an advocate, as opposed to almost half of the VIP group.

CPO lawyers. As expected, the VIP group had significantly more contact with a lawyer for their CPO case at both 3 and 6 months, $\chi^{2}(1, N=112)=59.90, p<.01$; 
Table 2. Range and Median Level of Contact With Each VIP Partner for 3- and 6-Month Follow-Ups

\begin{tabular}{|c|c|c|c|c|c|c|}
\hline & \multicolumn{3}{|c|}{ VIP } & \multicolumn{3}{|c|}{ Services-as-usual } \\
\hline & Range & $M(S D)$ & Median & Range & $M(S D)$ & Median \\
\hline Advocate 3 months* & $0-90$ & $6.75(16.50)$ & 3 & $0-20$ & $1.49(2.78)$ & 0 \\
\hline Advocate 6 months* & $0-10$ & $1.66(2.57)$ & 0 & $0-2$ & $0.28(0.62)$ & 0 \\
\hline Prosecutor 3 months & $0-22$ & $2.40(3.65)$ & I & $0-72$ & $2.83(8.59)$ & I \\
\hline Prosecutor 6 months & $0-12$ & $1.29(2.50)$ & 0 & $0-3$ & $0.52(0.90)$ & 0 \\
\hline CPO lawyer 3 months* & $0-90$ & $8.88(19.17)$ & 5 & $0-10$ & 0.31 (I.3I) & 0 \\
\hline CPO lawyer 6 months* & $0-90$ & $3.6 \mid$ (I5.59) & 0 & $0-3$ & $0.09(0.48)$ & 0 \\
\hline
\end{tabular}

Note:VIP = Victim-Informed Prosecution Project; $C P O=$ civil protection order.

$*$ Difference between VIP and services-as-usual significant at $p<.0$ I.

$\chi^{2}(1, N=88)=18.65, p<.01$, because only 8 of the control group participants had CPO lawyers at all.

Prosecutors. The VIP and services-as-usual groups did not differ in the number of contacts they reported with prosecutors at either the 3- or 6-month mark, $t(110)=-.91, p=.37$; $\chi^{2}(1, N=92)=.36, p=.55$. Slightly (but not significantly) more of the services-as-usual group had no contact with a prosecutor in the first 3 months $(38.9 \%$ vs. $27.5 \%)$. There was a similar pattern at 6 months, with $70.7 \%$ of the services-as-usual group reporting no contact with prosecutors compared to $64.7 \%$ of the VIP group.

\section{Coordination}

Table 3 details the percentage of VIP cases for which each type of coordination took place. Basic information sharing was relatively common, since the team met as a group for all cases. Prosecutors and civil lawyers shared facts about the case in three quarters $(75.7 \%)$ of cases and had "meaningful" discussions about case-related decisions in almost two thirds of cases (62.9\%). This is a significant departure from services-as-usual, where generally no information is exchanged. However, coordination that went beyond exchange of information (which might take place only in the context of the group meetings or at the initiation of CPO lawyers) was much rarer. For example, CPO lawyers only attended meetings between victims and prosecutors in 13 cases (38.2\%), and advocates only attended such meetings in 5 cases (14.7\%). For civil lawyers and advocates to attend such meetings would mean that the prosecutors had gone out of their way to invite them.

\section{Victim Perception of Voice}

As described in the Measures section, perceived voice was measured at 6 months, looking back over the participant's experience with the court process. Women in both groups rated their level of voice highly, with the mean scale total of $10.10(S D=2.60$, 
Table 3. Percentage of VIP Cases for Which Each Type of Coordination Took Place

\begin{tabular}{lllc}
\hline VIP partners & \multicolumn{1}{c}{ Item } & \multicolumn{1}{c}{$\begin{array}{c}\text { Percentage }(n) \\
\text { endorsed }\end{array}$} \\
\hline CPO lawyers and prosecutors & Telephone relationship $^{\mathrm{b}}$ & 37 & $64.9(24)$ \\
& Meaningful discussions $^{\mathrm{b}}$ & 35 & $62.9(22)$ \\
& Attended meetings $^{\mathrm{c}}$ & 34 & $38.2(13)$ \\
& Shared facts about case & 37 & $75.7(28)$ \\
& Shared testimony & 34 & $29.4(10)$ \\
& Shared exhibits & 36 & $55.6(20)$ \\
& Facilitated police & $16.1(5)$ \\
Advocates and prosecutors & Witness conferences & 31 & $14.3(5)$ \\
CPO lawyers, advocates, and & Attended meetings & 35 & $14.7(5)$ \\
prosecutors & Met as a group & 34 & $100(43)$ \\
\hline
\end{tabular}

Note:VIP = Victim-Informed Prosecution Project; CPO = civil protection order.

a. Number of cases for which item was answered. Items were coded retrospectively, and in some cases, information in files was not sufficient to answer all items.

b. See measures for wording of item.

c. Attended meetings = Georgetown attended meetings between the prosecutor and the client.

d. Facilitated police $=$ Georgetown collaborated with police, and this was facilitated by the prosecution.

e. Witness conferences = Georgetown attended witness conferences held by the prosecution.

f. Attended meetings = Advocates attended meetings between prosecutor and victim.

g. Met as a group $=$ VIP partners met as a group to discuss this case.

median $=11)$ for VIP participants and $9.50(S D=2.75$, median $=9)$ for services-as-usual participants, and more than a third of the total sample at the maximum score.

\section{Relationship Between VIP and Voice}

At the 6-month follow-up, we investigated whether degree of contact with advocates, CPO lawyers, prosecutors, and overall participation in the program as opposed to services-asusual predicted perceived level of voice in the process. As detailed in Table 4, being in the VIP group as opposed to services-as-usual was not related to perceived voice. Considering contact with system actors between intake and 3 months, contact with advocates was related to significantly greater perceived voice and contact with CPO lawyers marginally so $(p=.07)$. There was no relationship between prosecutor contact either at 3 months or at 6 months, when only contact with advocates was related to greater perceived voice.

Looking further at these mixed findings, we noted that the amount of contact between prosecutors and victims was far less than we had expected, particularly between 3 and 6 months after intake. Since the relationship between prosecutor and victim was a central component of VIP, as a post hoc exploration we investigated whether there was a program effect for those participants with ongoing contact with prosecutors. First, we looked at the subgroup of participants who had any contact with prosecutors between 3 and 6 months ( $n=29 ; 12$ VIP and 17 services-as-usual). Indeed, we found that VIP was related to 
Table 4. Relationship Between VIP, Program Components, and Perceived Voice at 6 Months

\begin{tabular}{lcc}
\hline & Relationship with voice & Group differences $^{\mathrm{a}}$ \\
\hline VIP versus services-as-usual & $\mathrm{NS}$ & $10.10(2.60)$ versus \\
Advocate & & $9.50(2.75)$ \\
$\quad \begin{array}{l}\text { Amount of contact in first 3 months } \\
\text { Contact from 3-6 months (yes/no) }\end{array}$ & $t(81)=-2.18 ; p=.03$ & $\mathrm{r} / 0.60(2.25)$ versus \\
CPO lawyer & & $9.34(2.80)$ \\
Amount of contact in first 3 months & $r_{\mathrm{s}}=.20 ; p=.07$ & $\mathrm{n} / \mathrm{a}$ \\
Contact from 3-6 months (yes/no) & $\mathrm{NS}$ & $9.00(2.77)$ versus \\
& & $9.78(2.71)$ \\
Prosecutor & $\mathrm{NS}$ & $\mathrm{n} / \mathrm{a}$ \\
Amount of contact in first 3 months & $\mathrm{NS}$ & $9.50(3.00)$ versus \\
Contact from 3-6 months (yes/no) & & $9.82(2.55)$ \\
\hline
\end{tabular}

Note: For $t$ tests, the square root of the voice scale score was used to reduce skew; VIP =Victim-Informed Prosecution Project; $\mathrm{CPO}=$ civil protection order; $\mathrm{n} / \mathrm{a}=$ not applicable.

a. Refers to mean and standard deviation (within parentheses) of perceived victim voice for groups being compared.

greater perceived voice in this subgroup, $t(26)=2.07, p=.05$. Second, we expanded our timeframe and looked at the subgroup of participants who reported greater than two contacts with prosecutors over the entire 6 months of follow-up $(n=47 ; 17$ VIP and 29 services-as-usual). In this group, VIP was associated with greater perceived voice at the level of a trend, $t(44)=1.83, p=.07$. One reason for such ongoing contact might be the severity of the case being processed. In particular, felonies take longer to be prosecuted and receive additional attention from prosecutors in the process. Exploring this possibility, we found that cases categorized as felonies were overrepresented in the group with contact between 3 and 6 months $\left(33.3 \%\right.$ vs. 11.51\%), $\chi^{2}(1, N=88)=6.01, p=.01$, and in the group with two or more contacts over 6 months but not significantly so $(23.9 \%$ vs. $10.3 \%), \chi^{2}(1, N=85)=2.71, p=.1$.

\section{Discussion}

\section{Summary of Findings}

In this evaluation, VIP participants received a different level of services than did the services-as-usual group, in that they had a great deal of contact with advocates and with CPO lawyers at both 3 and 6 months after entering the system. They did not, however, have significantly more contact with prosecutors. Coordination, which was the heart of the VIP program, was achieved to a limited degree. The VIP group discussed all cases as a group and exchanged case-specific information, which is a large departure from services-asusual. However, collaboration that would have required the prosecutors to initiate contact 
to include team members in their work on a case, such as meeting together with the victim, was much rarer. Even maintaining a telephone relationship with prosecutors with respect to a particular case was harder to achieve than one might expect, with a third of the cases not endorsing this item.

Despite this imperfect implementation, there is some evidence that the program was associated with increased perceived victim voice in the court process. Greater contact with advocates and CPO lawyers (at the level of a trend) during the first 3 months, and with advocates at 6 months, was related to greater voice. These were the services that VIP was successful in intensifying. While the VIP group did not report more voice than the servicesas-usual group in the full sample, a post hoc examination of those who had more contact with prosecutors yielded some suggestive findings. Among those who had contact with prosecutors between 3 and 6 months, and among those who reported greater than two contacts with prosecutors over the entire 6 months, VIP was associated with greater perceived voice (the latter finding at the level of a trend).

From these findings, it appears that ongoing contact between the prosecutor and victim may be a necessary ingredient for a model such as VIP to have its desired impact. In other words, perhaps VIP had a greater chance of having an effect when there was more of a relationship between the prosecutor and victim to facilitate. While VIP did not increase contact between prosecutors and victims overall, the program was associated with a greater likelihood of a case being designated a felony, and felonies were more likely to receive ongoing attention from prosecutors. We attribute the overrepresentation of felonies in the VIP group to the efforts of civil lawyers and advocates to bring relevant history and context to bear on these decisions. In sum, it appears that VIP may have the most potential for a particular group of cases - those where there is ongoing contact with the prosecutor-potentially because of the case's felony status.

\section{Limitations}

There are significant limitations to the data presented here. First, both the nature of the sample (urban, primarily African American, and low income) and the particularities of the Washington, D.C. system should be noted in generalizing of results. Second, sample attrition at follow-up is an inevitable component of longitudinal work with this population, weakening both power and generalizability. However, the fact that we were able to follow up with the VIP group better than the services-as-usual group likely means that the group differences we found in level of contact with the system was an underestimate; those participants who were hard for us to reach were likely hard for court staff to reach as well. Third, the small sample size in this study makes our results suggestive rather than conclusive. Fourth, the fact that participant responses to the voice items were high across the board may reflect a lack of sensitivity of our measure; this represents an important direction for future research. It is also possible that lack of voice is not as much of a problem in this sample as prior work has suggested, a question that could be explored if better strategies for measurement are developed (see Russell, 2002, for important groundwork). Finally, the VIP and services-as-usual groups differed in that VIP cases were more likely to be felonies. There is 
a possibility that this difference indicates a problem with our recruitment strategy, but we think this interpretation is unlikely. The groups did not differ with respect to history of violence, suggesting that the VIP cases were not overall more severe. Instead, we believe this difference was a result of the coordination in VIP, as described earlier.

Given these limitations, our conclusions must be tentative and certainly should not be assumed to be generalizable without further exploration. A guiding principle in the implementation of empirically based programs is to take careful note of the setting in which the programs are carried out and modify as necessary to fit one's own context (Dalton, Elias, $\&$ Wandersman, 2007). The nature of the system in Washington, D.C. affected the viability of VIP in important ways. Here we identify those components of context that would provide most fertile ground for such a program, with the hope that those interested in similar models might evaluate the fit with their particular setting.

\section{VIP in Context: Recommendations for Future Implementation}

Minimize turnover. During the course of the VIP program, there was a high rate of turnover in the USAO at all levels. At the highest level, this weakened the institutional commitment of the office. The lead prosecutor also turned over at least seven times, preventing some from fully coming up to speed on the mission of or the protocols of the program and hindering efforts to build relationships among team members. As the supervisor of the prosecutors actually handling VIP cases, the lead prosecutor was the conduit for all team member input to the prosecution; when she was not committed to this role, the program foundered. Attorneys in the domestic violence section of the USAO- those the lead prosecutor was supervising on VIP cases - stay for only 4 to 6 months before they rotate to a different unit. Turnover at this level meant there would be little or no personal commitment to VIP among this group, and educating newcomers about VIP was one among many pressing training needs. Furthermore, it meant that cases might change hands midstream, potentially making the relationship between victim and prosecutor more difficult to facilitate. Increasing this challenge, during the final years of VIP, the USAO prosecutors began to prosecute cases on the horizontal rather than vertical model. Under the horizontal model, a prosecutor handles a particular aspect of cases and allows other prosecutors to perform subsequent aspects, lessening the long-term investment a prosecutor and victim might have in each other. In a vertical model, one prosecutor takes responsibility for all aspects of a case from its inception to its resolution.

In some jurisdictions, there is naturally less turnover than in Washington, D.C., and vertical models of prosecution are still employed. These would be good sites for experimentation. Furthermore, in seeking out partners for such a program, the potential for turnover should be at the forefront of the program developer's mind. Finally, if the lead VIP prosecutor had handled cases herself, as might be the case in jurisdictions with dedicated domestic violence prosecutors, this would have reduced the impact of the constant turnover of prosecutors under her supervision. This was the original plan in VIP and likely would have worked better than the more diffuse model that evolved. 
Elicit an enduring commitment from all team members. Because none of the team members had exclusive responsibility for the recruitment of VIP cases, VIP clients were recruited in a haphazard fashion and at a rate that often fell short of the full capability of the team. The slow momentum of VIP formed a vicious circle with the rate of turnover just described. At any given time, there were not many cases for newcomers at all levels to learn protocols and see benefits of the program. This lack of momentum failed to sweep up those who were more doubtful about the potential of the program, which then made it more difficult to establish and maintain a recruitment system.

Developing such a system requires an institutional commitment at high levels to create and enforce protocols. Clearly, lack of turnover could be of considerable help here. But underlying both of these issues is the need for an enduring commitment to the project from all partners. Such a commitment could stem from several sources. Optimally, preexisting professional or personal relationships among team members could form a solid foundation for ongoing collaboration. When this was the case in VIP, the program thrived. In the absence of such luck, a commitment to a funder can serve a similar purpose. VIP initially did have funding, and this was a great help in bringing partners on board and remaining true to our mission. Finally, a common commitment to rigorous experimentation, undergirded by a sense that business-as-usual is not serving a common goal, can bring partners together as well. Attention to these issues by program developers at the outset might both reduce turnover and increase the momentum of the project, in addition to providing a foundation to weather whatever difficulties arise along the way.

Gauge and manage institutional pressures. When VIP was working well, partners learned a great deal from each other. Prosecutors educated other members about their overwhelming workload - typically over 100 cases at any given time. With such a burden, prosecutors had little time to do anything over and above the essentials of their work. Attending to victim concerns is not often perceived as one of these essentials.

In some jurisdictions, the workload of prosecutors might be less intense. In systems similar to Washington, the workload prosecutors shoulder is a problem with implications far beyond the focus of this article. Addressing it requires system change and an infusion of resources that is unlikely, at least in the short term. The question here is what makes it possible to bring prosecutors on board a project such as VIP in this difficult context. We believe there are two strategies that increase the likelihood of that goal. First is facilitating the enduring commitment to the project just described, at its inception. Such a commitment from high levels in the prosecutor's office could help to make a program like VIP a priority. For example, when the VIP program was initiated, the USAO committed to designate one prosecutor to VIP and to limit her non-VIP work to allow her to focus on the collaborative aspect of the program. (As personnel turned over, this commitment was abandoned.) Second, in a later article, we will explore whether VIP produced outcomes consonant with the USAO's primary focus, offender accountability. In other words, do we have evidence that such an approach can be useful in reaching shared goals? Such data must be collected and brought to bear if overburdened offices such as the one in our city are to be convinced that a victim-oriented perspective is worthwhile. 


\section{Conclusion and Opportunities for the Future}

This study supports the important role victim advocates (including attorneys working on behalf of the victim) can play in victims' overall experience in the court system. But going beyond the provision of one service or another, our results suggest that the model on which VIP was based, coordination through the life of a case to amplify the voice of the victim in prosecution, has potential. We believe two recommendations are most important in coaxing fruit from future opportunities. First, for program developers, the relationships among team members must be a focus from the beginning, either in building on preexisting relationships or carefully setting the stage to engender new ones. Obstacles to those relationships can effectively kill the program. Second, for researchers, to evaluate victim-oriented approaches to IPV intervention, the field needs to develop better measures for assessing victim-oriented outcomes such as voice and empowerment.

Collaboration among various groups and institutions working to address IPV has become a priority for funders and policy makers. A growing body of research supports this direction for program development in general, but the field is in need of specific information about how this should be done. Answering that need requires innovation and evaluation in a multidisciplinary context - a work-intensive and complex endeavor but one that we believe is critical to moving the field toward more effective models of IPV intervention.

\section{Acknowledgments}

The program described in this article could not have been attempted without the efforts of many outstanding staff at the U.S. Attorney's Office, District of Columbia Coalition against Domestic Violence, and Georgetown Law School. The authors would like to thank particularly those whose dedication and enthusiasm saw the program through critical moments: Robert Spagnoletti, Kelly Higashi, Pam Satterfield, Cynthia Schnaeder, Bart Aronson, Elana Tyrangiel, Nicole Bove, Karen Daniel, and Ken Noyes. The authors also thank their invaluable research assistants, including Lori Mihalich, Rebecca Duckworth, Fedra Sanchez, Brittany Key, and Adriana Pilafova.

\section{Declaration of Conflicting Interests}

The author(s) declared no potential conflicts of interest with respect to the authorship and/or publication of this article.

\section{Funding}

This research was supported in part by the STOP (Services * Training * Officers * Prosecutors) Violence Against Women Formula Grants Program, and by grants from the Beech Street Foundation and the RGK Foundation.

\section{Note}

1. Because the District of Columbia is not a state, the U.S. Attorney's Office (but not the Domestic Violence Unit) prosecutes local crimes in addition to federal. This does not affect the way that domestic violence cases are prosecuted. 


\section{References}

Bell, M. E. (2007). Empowerment and disempowerment for victims of intimate partner violence: An overview of the effects of criminal justice system practices. In K. KendallTackett \& S. Giacomoni (Eds.), Intimate partner violence (pp. 1-15). Washington, DC: Civic Research Institute.

Bennett, L. E., Goodman, L. A., \& Dutton, M. A. (1999). Systemic obstacles to the criminal prosecution of a battering partner: A victim perspective. Journal of Interpersonal Violence, 14, 761-772.

Bennett Cattaneo, L., Bell, M. E., Goodman, L. A., \& Dutton, M. A. (2007). Intimate partner violence victims' accuracy in assessing their risk of re-abuse. Journal of Family Violence, $22,429-440$.

Crawford v. Washington, 541 U.S. 36 (2004).

Dalton, J. H., Elias, M. J., \& Wandersman, A. (2007). Community psychology: Linking individuals and communities (2nd ed.) Belmont, CA: Wadsworth/Thompson Learning.

Davis and Hammon v. Washington, 547 U.S. 813 (2006).

Epstein, D. (1999). Effective intervention in domestic violence cases: Rethinking the roles of prosecutors, judges, and the court system. Yale Journal of Law and Feminism, 11(3), 9-11.

Epstein, D. (2002). Procedural justice: Tempering the state's response to domestic violence. William \& Mary Law Review, 43, 1843-1905.

Epstein, D., Bell, M. E., \& Goodman, L. A. (2003). Transforming aggressive prosecution policies: Prioritizing victims' long-term safety in the prosecution of domestic violence cases. Journal of Gender, Social Policy, \& the Law, 11, 465-498.

Erez, E., \& Belknap, J. (1998). In their own words: Battered women's assessment of the criminal processing system's response. Violence \& Victims, 13, 251-268.

Fagan, J. (1996). The criminalization of domestic violence: Promises and limits (Document No. 157641). Washington, DC: National Institute of Justice.

Fleury-Steiner, R. E., Bybee, D., Sullivan, C. M., Belknap, J., \& Melton, H. C. (2006). Contextual factors impacting battered women's intentions to reuse the criminal legal system. Journal of Community Psychology, 34, 327-342.

Ford, D. A., \& Regoli, M. J. (1993). The criminal prosecution of wife assaulters: Process, problems and effects. In N. Z. Hilton (Ed.), Legal responses to wife assault: Current trends and evaluation (pp. 131-151). Thousand Oaks, CA: Sage.

Gavin, C., \& Puffett, N. K. (2005). Criminal domestic violence case processing: A case study of the five boroughs of New York City. New York: Center for Court Innovation.

Gillis, J. R., Jebely, P., Orekhovsky, V., Ostovich, E. M., MacIsaac, K., Sagrati, S., et al. (2006). Systemic obstacles to battered women's participation in the judicial system: When will the status quo change? Violence Against Women, 12, 1150-1168.

Hanna, C. (1996). No right to choose: Mandated victim participation in domestic violence prosecutions. Harvard Law Review, 109, 1850-1851.

Hotaling, G., \& Buzawa, E. (2003). Forgoing criminal justice assistance: The non-reporting of new incidents of abuse in a sample of domestic violence victims (Document No. 195667). Washington, DC: National Institute of Justice. 
Jordan, C. E. (2004). Intimate partner violence and the justice system: An examination of the interface. Journal of Interpersonal Violence, 19, 1412-1434.

Kohn, L. S. (2008). The justice system and domestic violence: Engaging the case but divorcing the victim. New York University Review of Law and Social Change, 32(2), 191-252.

Landau, T. C. (2000). Women's experiences with mandatory charging for wife assault in Ontario, Canada: A case against the prosecution. International Review of Victimology, 7, 141-157.

Lewis, R. (2004). Making justice work: Effective legal interventions for domestic violence. British Journal of Criminology, 44, 204-224.

Newmark, L., Harrell, A., \& Salem, P. (1995). Domestic violence and empowerment in custody and visitation cases. Family and Conciliation Courts Review, 1(33), 30-62.

Rebovich, D. J. (1996). Prosecution response to domestic violence: Results of a survey of large jurisdictions. In E. S. Buzawa \& C. G. Buzawa (Eds.), Do arrests and restraining orders work? (pp. 176-191). Thousand Oaks, CA: Sage.

Russell, M. (2002, April). Measures of empowerment for women who are victims of violence and who use the justice system. Vancouver, British Columbia, Canada: Victim Services Division, BC Ministry of Public Safety and Solicitor General.

Straus, M. A., Hamby, S. L., Boney-McCoy, S., \& Sugarman, D. B. (1996). The Revised Conflict Tactics Scales (CTS2): Development and preliminary psychometric data. Journal of Family Issues, 17, 283-316.

Tabachnick, B. G., \& Fidell, L. S. (2007). Using multivariate statistics (5th ed.). Boston: Allyn \& Bacon.

Tolman, R. M. (1999). The validation of the Psychological Maltreatment of Women Inventory. Violence and Victims, 14, 25-37.

Zweig, J. M., \& Burt, M. R. (2007). Predicting women's perceptions of domestic violence and sexual assault agency helpfulness: What matters to program clients? Violence Against Women, 13, 1149-1178.

\section{Bios}

Lauren Bennett Cattaneo, $\mathrm{PhD}$, is an assistant professor in the psychology department at George Mason University. Her research focuses on the interaction between victims of intimate partner violence and the institutions, agencies, and policies that are designed to help them. Recent work has centered on risk assessment, patterns of and obstacles to helpseeking with particular attention to socioeconomic status, innovations in the court system's approach to domestic violence cases, and defining and measuring victim-centered practice.

Lisa A. Goodman, PhD, is an associate professor in the Department of Counseling and Applied Developmental Psychology at Boston College. She is the author of more than 75 articles on community responses to intimate partner violence, the effects of partner violence on marginalized women, and innovative community-based mental health practices for vulnerable populations. She is cofounder of the ROAD Advocacy Resource Team, an advocacy project for low-income women struggling with depression. Her recent book, coauthored with Deborah Epstein and published by the American Psychological Association in 2008, is titled Listening to Battered Women: A Survivor-Centered Approach to Advocacy, Mental Health, and Justice. 
Deborah Epstein, JD, associate dean of clinical programs and codirector of the domestic violence clinic at Georgetown University Law Center, has spent more than 20 years working as an advocate for victims of domestic violence. She has served as cochair of the DC Superior Court's effort to implement its domestic violence unit, codirector of the DC Superior Court's Domestic Violence Intake Center, director of the Emergency Domestic Relations Project, chair of the DC Domestic Violence Fatality Review Board, a member of the DC Mayor's Commission on Violence Against Women, a member of the DC Superior Court Domestic Violence Coordinating Council, and a member of the DC Coalition Against Domestic Violence board of directors.

Laurie S. Kohn, JD, is a visiting professor of law at Georgetown University Law Center and the codirector of Georgetown's Domestic Violence Clinic. She supervises students representing victims of domestic violence, teaches the clinic seminar, and litigates domestic violence cases. She regularly conducts trainings and has written extensively about domestic violence. She is cochair of the DC Superior Court Domestic Violence Unit Task Force, cochair of the DC Bar Family Law Section, a complaint examiner for the DC Office of Police Complaints, and a board member of the Frederick B. Abramson Memorial Foundation. She received her LLM and law degrees from Georgetown University and her AB from Harvard College.

Holly A. Zanville received a doctorate in clinical psychology at George Mason University in 2009. She received her BA in psychology from the University of Pennsylvania in 2002. Her research focuses on trauma services for community mental health consumers and on intimate partner violence. She is also interested in public policy related to mental health. She is currently completing a postdoc at the Fifth Avenue Center for Counseling and Psychotherapy in New York City. 